\title{
ARTIGOS
}

\section{VISCEROTOMIA HEPÁTICA (SUA CONTRIBUIÇÃO AO ESTUDO DA NOSOLOGIA REGIONAL)}

\author{
Zilton A. Andrade e Aryon A. Barbosa Junior
}

\begin{abstract}
Foi feita uma avaliação histopatológica de 702 fragmentos de tecido hepático obtidos pela antiga SUCAM no sul do Estado da Bahia no período que vai de 1981 a 1991. Apenas em 17,7\% dos casos ofigado foi considerado histologicamente normal. Mais de um terço dos casos exibia intensa esteatose, provavelmente causada por desnutrição grave afetando crianças nos primeiros anos de vida. Nos demais, as alterações indicativas de fibrose, tuberculose, esquistossomose e hepatites apareceram como processos importantes pela sua gravidade $e$ frequência. Além disso, uma variada gama de processos patológicos hepáticos pôde também ser reconhecida. Sugere-se que o material de viscerotomia merece um exame histológico mais detalhado, pois desta maneira poderáfornecer dados de valor para a identificação de processos patológicos que afetam populações vivendo em áreas remotas do nosso país.
\end{abstract}

Palavras-chaves: Viscerotomia. Patologia hepática. Esteatose hepática.

A viscerotomia consistena retirada post-mortem de um fragmento de órgão através de um aparelho especial (viscerótomo) para posterior análise histopatológica. Foi amplamente empregada no Brasil desde 1930 para a retirada de fragmentos de fígado, como uma forma de vigilância epidemiológica para se detectar casos de febre amarela. Atualmente, vem sendo ainda utilizada em algumas regiões do Brasil, entre as quais a área assinalada no sul da Bahia (Figura 1), onde ocorreram casos de febre amarela, embora desde 1950 tal doença não tenha mais sido detectada na referida área.

O estudo histológico de material obtido por viscerotomia já possibilitou, no passado, não só o reconhecimento da febre amarela, mas o diagnóstico de toxoplasmose, histoplasmose, hepatite grave commicroesteatose (febre de Lábrea) e a identificação de um surto de leishmaniose visceral (calazar) no Nordeste brasileiro 6811 .

Entre 1981 e 1991 o Serviço de Patologia do Centro de Pesquisas Gonçalo Moniz/FIOCRUZ solicitou e recebeu da antiga SUCAM, com maior ou menor regularidade, amostras de fígado obtidas por viscerotomia realizada em várias localidades do

\footnotetext{
Centro de Pesquisas Gonçalo Moniz/FIOCRUZ. Salvador, BA, Brasil

Endereço para correspondência: Dr. Zilton A. Andrade. R. Valdemar Falcão 121, 40295-001 Salvador, BA.

Fax: (071) 359-4292.

Recebido para publicação em 22/09/93.
}

sul da Bahia. O interesse do Serviço era verificar qual o potencial do método para fomecer informações sobre a patologia hepática em populações que vivem em áreas remotas do país. Embora se possa facilmente antecipar as grandes limitações da viscerotomia, um procedimento limitado a pacientes que vêm a falecer no curso de doença aguda febril, com máximo de 10 dias de evolução e sem maiores informações clínicas, para estudos sobre a patologia hepática, talvez haja vantagens em que este material seja examinado por patologistas, ao invés de o ser apenas por técnicos encarregados da despistagem de casos de febre amarela. É fundamentalmente este aspecto, que o presente estudo procura demonstrar.

\section{MATERIAL E MÉTODOS}

Os fragmentos de tecido hepático correspondente a 702 cadáveres foram recebidos já fixados em formol 10\%. Para obtê-los foi feita uma pequena inicisão cutânea na região do hipocôndrio direito, logo abaixo da reborda costal, onde foi introduzido o viscerótomo. Os fragmentos de fígado recebidos no laboratório mediam aproximadamente $2 \times 1 \times 1 \mathrm{~cm}$ nas maiores dimensões, sendo portando comparáveis ao material regularmente obtido através de biópsia cirúrgica. Seccionados em 2 a 3 blocos, os fragmentos foram incluídos em parafina e os cortes histológicos corados pela hematoxilina e eosina. Em casos especiais foram ainda empregados os seguintes métodos de coloração: picrosirius-red 
Andrade ZA, Barbosa Junior AA. Viscerotomia hepática (sua contribuição ao estudo da nosologia regional). Revista da Sociedade Brasileira de Medicina Tropical 27:69-73, abr-jun, 1994.

para colágeno, PAS, com e sem digestão prévia pela diástase, para estruturas contendo glico-proteínas, Sudan III para lípedes, reticulina de Gomori, Weigert-Van Gieson para tecido colágeno e elástico e o tricrômico de Masson. Em casos suspeitos de tuberculose, foi feita coloração pelo Método de Fite-Faraco para bacilos álcool-ácido resistentes. Os dados de identificação e procedência dos indivíduos que sofreram viscerotomia foram obtidos das fichas respectivas que acompanhavam os fragmentos entregues ao laboratório

\section{RESULTADOS}

Generalidades - Na Figura 1, está representado o mapa do Estado da Bahia, com destaque para as áreas donde provieram os casos. A maioria deles

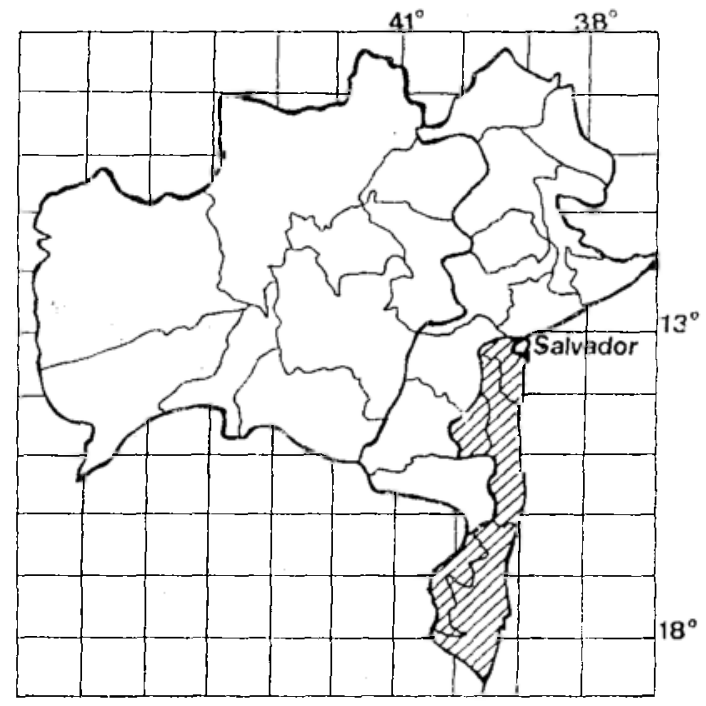

Figura I - Mápa do Es̃tadó da Bania, indicando na área tracejada a região de onde provieram os casos de viscerotomia hepática relatados no presente trabalho.

$(96,0 \%)$ se originou da micro-região cacaueira. $\mathrm{Na}$ Tabela 1, são apresentados os casos segundo os diagnósticos histopatológicos. As Tabelas subsequentes fornecen detalhes sobre os processos mais freqüentemente diagnosticados no material estudado. São também feitas referências sobre critérios diagnósticos e particularidades encontradas. Foi examinado um total de 702 casos, representados por $446(63,5 \%)$ indivíduos do sexo masculino e
Tabela 1 - Principais diagnósticos histopatológicos em 702 casos examinados após viscerotomia hepática.

\begin{tabular}{lrr}
\hline \multirow{2}{*}{ Diagnóstico } & \multicolumn{2}{c}{ Casos } \\
\cline { 2 - 3 } & $\mathrm{n}^{\circ}$ & $\%$ \\
\hline Esteatose & 268 & 38,1 \\
Doenças granulomatosas & 53 & 7,5 \\
Fibrose & 46 & 6,6 \\
Hepatites & 45 & 6,4 \\
Miscelânea & 84 & 12,0 \\
Fígado normal & 124 & 17,7 \\
Autólise & 79 & 11,3 \\
Outros órgãos & 3 & 0,4 \\
\hline Total & 702 & 100,0 \\
\hline
\end{tabular}

$256(36,5 \%)$ do sexo feminino. A média de idade foi de $29,2 \pm 28$ anos, a mediana foi 21 e a moda 1. $O$ indivíduo mais idoso tinha 90 anos de idade. Esteatose - O principal achado foi a esteatose e os vários tipos encontrados estão relacionados na Tabela 2. Todos estes casos representam exemplos em que

Tabela 2 - Tipos histologicos de esteatose hepática observados nomaterialde 702 viscerotomias.

\begin{tabular}{lr}
\hline Tipos & $\mathrm{N}^{\mathrm{O}}$ \\
\hline Macrovesicular & \\
$\quad$ difusa & 208 \\
$\quad$ periportal & 32 \\
$\quad$ centro-acinar & 16 \\
Microvesicular & 12 \\
\hline Total & 268 \\
\hline
\end{tabular}

a esteatose era a alteração única ou dominante. Do total de $268(38,1 \%)$ casos, 133 ocorreram em crianças que faleceram durante o primeiro ano de vida. Daquele total, 208 tinham esteatose difusa, sendo que 115 exibiam o grau máximo dessa alteração, com praticamente todos os hepatócitos contendo grandes vacúolos, com deslocamento do núcleo para a periferia da célula e com freqüente formação de cistos de gordura.

Os 12 casos com esteatose de tipo microvesicular apresentavam graus variáveis dessa alteração, mas todos exibiam tumefação dos hepatócitos atingidos. Em 4 casos, havia associação com necrose lítica ou coagulativa de hepatócitos e infiltração intralobular 
Andrade $Z$ A, Barbosa Junior AA. Viscerotomia hepática (sua contribuição ao estudo da nosologia regional). Revista da Sociedade Brasileira de Medicina Tropical 27:69-73, abr-jun, 1994.

e portal de leucócitos mononucleares, num quadro muito semelhante ao da hepatite de Lábrea. Entretanto, não foi visto quadro sugestivo de síndrome de Reye.

Doenças granulomatosas - Os tipos encontrados estão relacionados na Tabela 3 , perfazendo um total de $53(7,5 \%)$ casos em que a alteração principal consistia na presença de lesões granulomatosas.

Tabela 3 - Granulomas hepáticos observados no material de 702 viscerotomias.

\begin{tabular}{lc}
\hline Granulomas & $\mathrm{N}^{\mathbf{0}}$ \\
\hline Granulomas esquistossomóticos & 26 \\
Tuberculóides & 18 \\
$\quad$ c/ necrose caseosa & 5 \\
$\quad$ s/ necrose caseosa & 4 \\
Cicatrizados & 53 \\
\hline Total & \\
\hline
\end{tabular}

Quando foram encontrados ovos ou restos de ovos do Schistosoma mansoni no interior dos granulomas, eles foram classificados como esquistossomóticos. A presença de necrose de caseificação num granuloma contendo células epitelióides e células gigantes foi considerada como provável tuberculose. Quando faltava a caseose, tais granulomas foram classificados como tuberculóides. A coloração para bacilos álcoolácido resistentes (Fite-Faraco) foi sempre negativa. Cicatrizes arredondadas, pequenas, foram consideradas como granulomas cicatrizados, estivessem ou não presentes outros granulomas.

Fibroses - Em 46 (6,6\%) casos, a alteração principal foi a presença de fibrose hepática, a qual foi classificada pela sua localização e forma, tal como aparece na Tabela 4. Merecem destaque 3 casos em que a fibrose portal estava associada à destruição de ramos da veia porta, dispersão de feixes de fibras musculares lisas e presença de muitos vasos dilatados

Tabela 4 - Tipos de fibrose hepática encontrados em material de 702 viscerotomias.

\begin{tabular}{lr}
\hline Tipos de Fibrose & N \\
\hline Portal & 27 \\
Portal e septal & 15 \\
Esquistossomótica & 3 \\
Septal & 1 \\
\hline Total & 46 \\
\hline
\end{tabular}

ede paredes finas (lesão angiomatóide), classificados como fibrose esquistossomótica (lesão "pipestem" da esquistossomose).

Hepatites - Em $45(6,4 \%)$ casos, havia densos infiltrados de células mononucleares nos espaços porta, caracterizando hepatite crônica (Tabela 5).

Tabela 5 - Tipos histológicos de hepatites encontrados no material de 702 viscerotomias.

\begin{tabular}{lr}
\hline Hepatites & $\mathrm{N}^{\mathrm{O}}$ \\
\hline Crônica persistente & 37 \\
Crônica ativa & 4 \\
Reativa inespecífica & 3 \\
"Eosinofílica" & 1 \\
\hline Total & 45 \\
\hline
\end{tabular}

Os quadros histopatológicos estavam dentro dos critérios habitualmente aceitos como clássicos ${ }^{5}$, sendo que nos casos de hepatite crônica ativa, além da infiltração da borda do parênquima pelas células inflamatórias havia colestase e evidência de regeneração hepato-celular. "Hepatite reativa" foi a expressão empregada para designar a presença concomitante de infiltrado portal, necrose de células isoladas e mobilização de células sinusoidais. A expressão "hepatite eosinofílica" foi aplicada a um caso em que o denso infiltrado portal era constituído predominantemente por eosinófilos. Nenhum dado morfológico foi encontrado para explicar a infiltração eosinofílica, inclusive qualquer traço de parasitismo. Miscelânea - Oitenta e quatro $(12,0 \%)$ casos, tiveram diagnósticos variados, os quais aparecem na Tabela 6. Dos casos de cirrose, um era de cirrose biliar secundária, provavelmente por atresia das vias biliares. Os 4 casos considerados como associados ao alcoolismo crônico exibiam corpúsculos hialinos de Mallory, esteatose e fibrose inetersticial, mas não apresentavam cirrose. Em 3 casos, a única alteração evidente encontrada foi uma pigmentação acastanhada dos hepatócitos centro-acinares, negativa ao PAS e à reação para ferro. Já a pigmentação por sobrecarga de ferro foi vista em 13 casos, mas aí sempre como manifestação secundária. O termo "septicemia crônica" é descritivo de uma interessante tumefação endotelial difusa, na presença de micro-abcessos esparsos. Entre as amostras recebidas, três representavam outros tecidos que não o fígado (intestino 2 vezes e 
Andrade ZA, Barbosa Junior AA. Viscerotomia hepática (sua contribuição ao estudo da nosologia regional). Revista da Sociedade Brasileira de Medicina Tropical 27:69-73, abr-jun, 1994.

Tabela 6 - Diagnósticos variados (miscelânea) feitos no material de 702 viscerotomias hepáticas.

\begin{tabular}{lr}
\hline Diagnóstico & $\mathrm{N}^{0}$ \\
\hline Congestão passiva crônica & 18 \\
Anemia falciforme & 10 \\
Cirrose hepática & 10 \\
Destrabeculação & 6 \\
Colestase & 6 \\
Atrofia hepática & 5 \\
Necrose centro-acinar & 5 \\
Doença alcoólica do figado & 4 \\
Hepatocarcinoma & 2 \\
Metástase de carcinoma & 2 \\
Abcessos hepáticos & 2 \\
Pigmentação hepatocitária & 3 \\
Doença de Hodgkin, hiperplasia & \\
$\quad$ nodular, glicogenose,linfocitosedos & \\
$\quad$ sinusóides, esclerose vascular, & \\
$\quad$ septicemia crônica", metaplasia & \\
$\quad$ mielóide, colangiteaguda supurativa, & \\
$\quad$ regeneração pseudo-acinar, peri- & \\
hepatite crônica. & 1 cada \\
\hline
\end{tabular}

Total 84

pulmão $1 \mathrm{vez}$ ), evidenciando desvio acidental do viscerótomo quando da colheita do material.

Figado nos limites da normalidade - Em 124 $(17,7 \%)$ casos, o aspecto histológico do fígado foi considerado totalmente normal 91 vezes; havia alterações mínimas em 11 casos e discreta congestão dos sinusóides e veias centro-acinares, provavelmente sobrevinda em período agônico ou terminal, nos restantes 22 casos. Em todas estas ocasiões, a estrutura histológica foi considerada dentro dos limites da normalidade.

A autólise post-mortem, a ponto de impossibilitar a avaliação histopatológica, aconteceu em 79 espécimens $(11,2 \%$ dos casos $)$.

\section{DISCUSSÃO}

O fígado esteve frequentemente lesado neste material obtido por viscerotomia de indivíduos falecidos com síndrome febril aguda. Apenas em $124(17,7 \%)$ casos, a histologia hepática pôde ser considerada como dentro dos limites da normalidade. O que concorreu para este resultado foi a presença predominante de crianças nos primeiros anos de vida exibindo extensa esteatose. Por sua vez, tais achados, indicativos de desnutrição grave e altas taxas de mortalidade infantil, refletem a situação sócio-econômica que prevalece no interior do paŕs, especialmente no Nordeste.

A tuberculose, no caso disseminada ou miliar, também aparece com uma freqüência preocupante. Embora haja dados na literatura indicativos de que o fígado está frequentemente envolvido em casos de tuberculose ativa ${ }^{9}$, é possível que com o exame de uma diminuta porção de tecido hepático apenas uma pequena fração de casos tenha sido detectada.

A esquistossomose apareceu como uma endemia importante para a região, não só pelo encontro de granulomas contendo ovos do parasito, mas pela presença de 3 casos da forma hepato-esplênica da doença. Esta forma, se autóctone, reflete alta prevalência na área de onde ela se origina ${ }^{12}$. Quanto ao diagnóstico histopatológico, ele pode ser estabelecido com segurança, pelas alterações de fibrose porta e comprometimento característicos dos ramos da veia porta, mesmo na ausência de qualquer elemento parasitário ${ }^{2}$. Outras parasitoses, susceptiveis de reconhecimento pela histopatologia hepática, tais como a leishmaniose visceral, a histoplasmose, etc, foram particularmente procuradas, mas não foram detectadas.

Alguns diagnósticos feitos merecem esclarecimentos. O termo anemia falciforme foi empregado para os casos que exibiam intensa dilatação e congestão dos sinusóides com presença de hemácias falcizadas. Possivelmente, tais casos representem não a doença, mas apenas a presença do traço, poís a falcização das hemácias em heterozigotos pode vir a ser exagerada em condições de baixa tensão de oxigênio, como a que ocorre no período agônico ${ }^{3}$.

Entre os casos que exibiram esteatose microvacuolar, com hepatócitos transformados em células "espongiocitárias" ou "em mórula", 4 deles mostraram adicionalmente alterações de hepatite com necrose hepatocitária, mas sem colapso da trama, num quadro sugestivo da hepatite de Lábrea. Casos deste tipo têm sido observados fora da região amazônica ${ }^{1}{ }^{10}$, em áreas onde o vírus Delta não parece existir e estão a merecer uma investigação mais aprofundada.

O caso designado como "linfocitose dos sinusóides" apresentou achado semelhante ao que tem sido descrito na malária crônica acompanhada por esplenomegalia ${ }^{7}$. No presente material não foram encontrados indícios da existência de malária 
Andrade ZA, Barbosa Junior AA. Viscerotomia hepática (sua contribuição ao estudo da nosologia regional). Revista da Sociedade Brasileira de Medicina Tropical 27:69-73, abr-jun, 1994.

na região estudada.

O termo "destrabeculação" significa que os hepatócitos apareciam isolados, desarrumados, sem formar traves, um achado que para alguns constitui evidência diagnóstica de leptospirose grave ${ }^{4}$.

No mais, uma gama variada de alteraçōes hepáticas esteve presente. Devido à própria natureza desta comunicação não será adequado discutir aqui os detalhes histopatológicos dos respectivos casos. A lista dos diagnósticos deve servir como uma indicação de que o material, que continua sendo obtido em várias regiões do país, fornece informaçōes valiosas e deve merecer o interesse do patologista. Deve ficar claro que não estamos propondo a instalação de novos serviços de viscerotomia, mas apenas o melhor aproveitamento de um material onde ele já é rotineiramente obtido.

\section{SUMMARY}

As a part of a routine yellow fever surveillance programgoing on in the south of Bahia State, Brazil, liver fragments were obtained through post-mortem viscerotomy from 702 individuals who died after presenting acute febrile illness from 1981 up till 1991. Instead of being only screened for the presence of yellow fever, the liver tissue was thoroughly evaluated by histopathology. More than a third of the cases exhibited marked and diffuse steatosis occuring in malnourished infants and young children. Hepatic fibrosis, granulomatous disease compatible with disseminated tuberculosis, advanced schistosomiasis, chronic alcoholic injury, chronic hepatitis and cirrhosis were also frequently observed. A miscellaneous group of hepatic pathological processes were also recognized, which included such diverse entities as Hodgkin's disease, glycogenosis, sickle-cell disease, hepatocarcinoma, etc. Only 124 (17.7\%) cases showed normal hepatic histology. The wide possibility of histological diagnoses strongly indicates that the material obtained by viscerotomy can be further explored by an interested pathologist, to help in the understanding of nosology and epidemiology, concerning remote geographic areas where viscerotomy is being routinely performed. liver.

\section{REFERÊNCIAS BIBLIOGRÁFICAS}

1. Andrade ZA, Barbosa AA. Hepatite de Lábrea em Salvador, Bahia? (Apresentação de um possível caso). Memórias do Instituto Oswaldo Cruz 78:491496, 1983.

2. Andrade ZA, Peixoto E. Pathology of peri-portal fibrosis involution in human schistosomiasis. Revista do Instituto de Medicina Tropical de São Paulo 34:263-272, 1992.

3. Bauer TB, Moore GW, Hutchins GM. The liver in sickle-cell disease: a clinicopathologic study of 70 patients. American Journal of Medicine 69:833$845,1980$.

4. Brito T. On the pathogenesis of the hepatic and renal lesions in leptospirosis. Revista do Instituto de Medicina Tropical de São Paulo 10:238-241. 1968.

5. DeGroote J, Desmet VJ, Gedigk P, Korb G, Popper H, Poulsen H, Scheur PJ, Schmid M, Thaler H, Uehlinger F. A classification of chronic hepatitis. Lancet 2:626-628, 1968.

6. Dias LB, Coura JR. Hepatite de Lábrea: Estudo de revisão em viscerotomias hepáticas dos anos 19341940. Revista do Instituto de Medicina Tropical de São Paulo 27:242-248, 1985.

7. Fluck DJ, Hutt MS, Fluck D, Stuvier PC. Ultrastructure of hepatic sinusoids in the tropical splenomegaly syndrome. Transactions of the Royal Society of Tropical Medicine and Hygiene 67:638643, 1973.

8. Gast-Galvis A. Viscerotomia en Colombia. Resultados del examen histo-patologico de 20.000 muestras del higado humano. Revista Medica (Bogotá) 553:1-34, 1975.

9. Hunt JS, Silverstein MJ, Sparks FC, Haskoll CM, Pilch YH, Morton DL. Granulomatous hepatitis: a complication of BCG immunotherapy. Lancet 2:820-821, 1973.

10. Paiva LM, Kazen J, Miyaqui T, Barreto Neto $\mathbf{M}$. Esteatose microvesicular como substrato de hepatite aguda grave. Provável relação com hepatite de Lábrea. Arquivos Brasileiros de Medicina 57:7174, 1983.

11. Penna HA. Leishmaniose no Brasil. Brasil Médico 48:949-950, 1934.

12. World Health Organization. Epidemiology and control of schistosomiasis. Report of a WHO Expert Committee. Technical Report Series 643:3-62, 1980. 